Doug Geisler, Eva K. Grebel, and Dante Minniti, eds.

\title{
Comparative Classification of Globular Clusters in the Galaxy and LMC
}

\author{
Olga Yatsyk and Olexij Eigenson \\ Astronomical Observatory of Ivan Franko National University of Lviv, \\ Kyryla and Mephodia str.8, Lviv, 79005, Ukraine
}

\begin{abstract}
The distributions of 141 globular clusters in the Galaxy and 54 globular clusters in the LMC in space with coordinates being their dynamical parameters are considered by taxonomical analysis. The majority of clusters are shown to enter several taxons (classes) with narrow enough limits of these parameters. Classes are not isolated and continually transfer between each other. It possibly means an absence of significant gaps in clusters' formation process. Taxonomical analysis of the joint distribution for both samples showed that though LMC clusters essentially differ in color and mass in the space of their dynamical parameters some part of them are similar to Galaxy globular clusters.
\end{abstract}

\section{Introduction}

In the previous paper of the authors (Eigenson \& Yatsyk 1995) comparative classification of globular clusters in the Galaxy and M31 using taxonomical analysis was made. The accumulation of the homogeneous data of a large number of globular clusters on the LMC (Kontizas et al. 1987; Chrysovergis et al. 1989) has permitted to make similar investigation in the space of their observed dynamical parameters.

As before, the centroid method of taxonomical (cluster) analysis was used. In this paper we perform such an analysis of a data set on 54 LMC globular clusters (I variant), 141 Galactic ones (II) and joint distributions of these two sets (III). We use the following parameters of clusters: tidal radius $r_{t}$, core radius $r_{c}$, distance from rotation center $R_{R . C .}$. for LMC clusters, and from the galactic

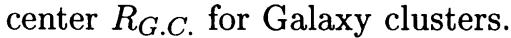

\section{Classification of LMC globular clusters}

The results of classification of $54 \mathrm{LMC}$ globular clusters can be illustrated graphically by a distance tree, or dendrogram, which can not be represented here. The average values of the cluster parameters for each taxon are set in Table 1. Column 1 gives the number of taxons, column $2-L$-values of combination level of a given taxon, column 3 - the number of clusters in the taxon, then the average values of the cluster parameters and their variances (in parentheses). The average values of the cluster parameters and their variance of the whole set are given below. 
Table 1. Mean parameters of taxons for LMC clusters

\begin{tabular}{|c|c|c|c|c|c|c|c|c|}
\hline Taxon No & $L$ & $\mathrm{n}$ & $\begin{array}{c}r_{t} \\
{[\mathrm{pc}]}\end{array}$ & $\begin{array}{c}r_{c} \\
{[\mathrm{pc}]}\end{array}$ & $\begin{array}{l}R_{R . C} \\
{[\mathrm{kpc}]}\end{array}$ & $(B-V)_{0}$ & $\left|M_{v}\right|$ & $\begin{array}{c}m \\
{\left[M_{\odot}\left(10^{5}\right]\right.}\end{array}$ \\
\hline 1 & 1.03 & 18 & $\begin{array}{l}63.0 \\
(2.9)\end{array}$ & $\begin{array}{c}2.1 \\
(1.0)\end{array}$ & $\begin{array}{c}1.71 \\
(0.51)\end{array}$ & $\begin{array}{c}0.32 \\
(0.29)\end{array}$ & $\begin{array}{c}7.89 \\
(0.85)\end{array}$ & $\begin{array}{c}1.4 \\
(0.3)\end{array}$ \\
\hline 2 & 1.20 & 9 & $\begin{array}{l}78.8 \\
(4.6)\end{array}$ & $\begin{array}{c}1.9 \\
(0.9)\end{array}$ & $\begin{array}{c}2.10 \\
(0.72)\end{array}$ & $\begin{array}{c}0.15 \\
(0.22)\end{array}$ & $\begin{array}{c}8.06 \\
(0.98)\end{array}$ & $\begin{array}{c}3.4 \\
(3.0)\end{array}$ \\
\hline 3 & 1.14 & 12 & $\begin{array}{l}47.0 \\
(4.9)\end{array}$ & $\begin{array}{c}2.3 \\
(1.0)\end{array}$ & $\begin{array}{c}3.12 \\
(0.59)\end{array}$ & $\begin{array}{c}0.24 \\
(0.25)\end{array}$ & $\begin{array}{c}7.54 \\
(0.94)\end{array}$ & $\begin{array}{c}0.4 \\
(0.1)\end{array}$ \\
\hline 4 & 0.81 & 5 & $\begin{array}{l}54.8 \\
(4.1)\end{array}$ & $\begin{array}{c}4.3 \\
(1.0)\end{array}$ & $\begin{array}{c}4.43 \\
(0.26)\end{array}$ & $\begin{array}{c}0.42 \\
(0.27)\end{array}$ & $\begin{array}{c}7.40 \\
(0.74)\end{array}$ & $\begin{array}{c}0.5 \\
(0.4)\end{array}$ \\
\hline 5 & 1.61 & 4 & $\begin{array}{l}50.7 \\
(7.1)\end{array}$ & $\begin{array}{c}5.8 \\
(1.5)\end{array}$ & $\begin{array}{c}1.80 \\
(0.85)\end{array}$ & $\begin{array}{c}0.42 \\
(0.23)\end{array}$ & $\begin{array}{c}7.15 \\
(0.10)\end{array}$ & $\begin{array}{c}0.6 \\
(0.2)\end{array}$ \\
\hline 6 & 1.79 & 3 & $\begin{array}{l}54.3 \\
(7.2)\end{array}$ & $\begin{array}{l}11.6 \\
(2.6)\end{array}$ & $\begin{array}{c}3.31 \\
(0.13)\end{array}$ & $\begin{array}{c}0.08 \\
(0.07)\end{array}$ & $\begin{array}{c}8.32 \\
(0.45)\end{array}$ & $\begin{array}{c}0.5 \\
(0.1)\end{array}$ \\
\hline NGC 1772 & & & 82.5 & 1.3 & 4.34 & & & 1.1 \\
\hline NGC 2231 & & & 37.0 & 1.4 & 5.67 & 0.52 & 5.30 & 0.1 \\
\hline NGC 1903 & & & 50.0 & 15.7 & 0.38 & 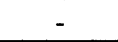 & - & 1.0 \\
\hline $\begin{array}{r}\text { All } \\
\text { sample }\end{array}$ & & & $\begin{array}{c}59.6 \\
(12.3)\end{array}$ & $\begin{array}{c}3.3 \\
(3.1)\end{array}$ & $\begin{array}{c}2.55 \\
(1.25)\end{array}$ & $\begin{array}{c}0.28 \\
(0.27)\end{array}$ & $\begin{array}{c}7.67 \\
(0.96)\end{array}$ & $\begin{array}{c}1.3 \\
(1.6)\end{array}$ \\
\hline
\end{tabular}

On the right part of Table 1 values of additional parameters are showed. These parameters do not enter the metrics, but also characterize the properties of the clusters and are "free parameters" in this approach. These are normal color $(B-V)_{0}$, module of absolute magnitude $\left|M_{v}\right|$ and mass $m / m_{\odot}$.

One can see that the average values of most parameters in taxons are essentially different. In the diagrams joining the taxon parameters of description pairwise there are regions of complete (or predominant) concentration of clusters belonging to the same taxon, but there are also some regions of overlapping. The corresponding taxons are not isolated but merge continuously one into another. This is confirmed by the behaviour of the value $L_{k+1} / L_{k}$, where $L_{k+1}=$ present, and $L_{k}=$ the largest of two previous levels of combination.

\section{Classification of Galaxy globular clusters}

In this variant the distribution of 141 galactic globular clusters is considered in the space of parameters from the catalogue of Harris (1996). There are 9 taxons and 2 clusters (which are not grouped). The transition among the taxons take place continuously too. This continuity is confirmed by plotting two-dimensional diagrams.

\section{Comparative classification of LMC and Galaxy globular clusters}

The globular clusters of Galaxy are very old objects (from the stellar evolutionary point of view), and represent only one special stage of their dynamical history. The Magellanic Clouds clusters have young, intermediate and old age. Therefore it is interesting, how the clusters will behave, when the taxonomical analysis is applied to the joint distribution of both samples. 
The eleven taxons are distinguished in this case. The average values of the cluster parameters for each taxon are given in Table 2. As was expected, on the dendrogram globular clusters form two large groups of taxons and two separate taxons, which differ more strongly from the main population combined than they differ from each other. That is No.10, which contains globular clusters of LMC with exceptionally large $r_{c}$ and taxon No.11 containing very remote globulars of Galaxy.

Table 2. Mean parameters of taxons for joint samples

\begin{tabular}{|c|c|c|c|c|c|c|c|c|c|c|}
\hline $\begin{array}{c}\text { Taxon } \\
\text { No. }\end{array}$ & $L$ & $\mathbf{n}$ & $n_{G}^{*}$ & $n_{L}^{* *}$ & $\begin{array}{c}r_{t} \\
{[\mathrm{pc}]}\end{array}$ & $\begin{array}{c}r_{c} \\
{[\mathrm{pc}]}\end{array}$ & $\begin{array}{c}R \\
{[\mathrm{kpc}]}\end{array}$ & $(B-V)_{0}$ & $\left|M_{v}\right|$ & $\begin{array}{c}m \\
{\left[M_{\odot}\left(10^{5}\right)\right]}\end{array}$ \\
\hline 1 & 0.37 & 68 & 68 & - & $\begin{array}{l}10.3 \\
(4.2)\end{array}$ & $\begin{array}{c}0.3 \\
(0.2)\end{array}$ & $\begin{array}{c}3.0 \\
(2.2)\end{array}$ & $\begin{array}{c}0.75 \\
(0.14)\end{array}$ & $\begin{array}{c}7.10 \\
(1.28)\end{array}$ & $\begin{array}{c}3.05 \\
(4.32)\end{array}$ \\
\hline 2 & 0.45 & 14 & 14 & - & $\begin{array}{l}19.2 \\
(2.9)\end{array}$ & $\begin{array}{c}0.4 \\
(0.4)\end{array}$ & $\begin{array}{c}7.2 \\
(2.5)\end{array}$ & $\begin{array}{c}0.66 \\
(0.09)\end{array}$ & $\begin{array}{c}7.94 \\
(0.84)\end{array}$ & $\begin{array}{c}4.28 \\
(4.04)\end{array}$ \\
\hline 3 & 0.72 & 29 & 29 & - & $\begin{array}{c}9.3 \\
(4.6)\end{array}$ & $\begin{array}{c}0.6 \\
(0.7)\end{array}$ & $\begin{array}{l}18.9 \\
(5.0)\end{array}$ & $\begin{array}{c}0.67 \\
(0.11)\end{array}$ & $\begin{array}{c}6.62 \\
(1.92)\end{array}$ & $\begin{array}{c}3.28 \\
(4.04)\end{array}$ \\
\hline 4 & 0.50 & 5 & 5 & - & $\begin{array}{l}12.7 \\
(2.5)\end{array}$ & $\begin{array}{l}2.1 \\
(0.4)\end{array}$ & $\begin{array}{c}6.4 \\
(1.6)\end{array}$ & $\begin{array}{c}0.74 \\
(0.11)\end{array}$ & $\begin{array}{c}6.04 \\
(1.74)\end{array}$ & $\begin{array}{c}0.98 \\
(0.93)\end{array}$ \\
\hline 5 & 1.72 & 5 & 5 & - & $\begin{array}{c}5.9 \\
(0.7)\end{array}$ & $\begin{array}{c}0.8 \\
(0.5)\end{array}$ & $\begin{array}{c}44.5 \\
(12.3)\end{array}$ & $\begin{array}{c}0.77 \\
(0.07)\end{array}$ & $\begin{array}{c}6.33 \\
(1.24)\end{array}$ & $\begin{array}{c}1.24 \\
(0.93)\end{array}$ \\
\hline 6 & 0.82 & 23 & 1 & 22 & $\begin{array}{l}54.7 \\
(8.3)\end{array}$ & $\begin{array}{c}3.0 \\
(0.7)\end{array}$ & $\begin{array}{c}2.8 \\
(1.2)\end{array}$ & $\begin{array}{c}0.38 \\
(0.30)\end{array}$ & $\begin{array}{c}7.71 \\
(1.10)\end{array}$ & $\begin{array}{c}1.38 \\
(2.81)\end{array}$ \\
\hline 7 & 0.73 & 19 & 2 & 17 & $\begin{array}{c}69.8 \\
(10.1)\end{array}$ & $\begin{array}{l}1.2 \\
(0.5)\end{array}$ & $\begin{array}{c}2.4 \\
(1.6)\end{array}$ & $\begin{array}{c}0.30 \\
(0.29)\end{array}$ & $\begin{array}{c}7.97 \\
(0.75)\end{array}$ & $\begin{array}{c}2.90 \\
(3.00)\end{array}$ \\
\hline 8 & 0.79 & 17 & 12 & 5 & $\begin{array}{l}35.2 \\
(6.9)\end{array}$ & $\begin{array}{l}1.0 \\
(0.4)\end{array}$ & $\begin{array}{c}6.4 \\
(3.9)\end{array}$ & $\begin{array}{c}0.58 \\
(0.19)\end{array}$ & $\begin{array}{c}7.80 \\
(1.04)\end{array}$ & $\begin{array}{c}3.31 \\
(3.80)\end{array}$ \\
\hline 9 & 1.15 & 5 & - & 5 & $\begin{array}{l}53.2 \\
(3.9)\end{array}$ & $\begin{array}{c}6.0 \\
(0.9)\end{array}$ & $\begin{array}{c}3.1 \\
(1.1)\end{array}$ & $\begin{array}{c}0.15 \\
(0.10)\end{array}$ & $\begin{array}{c}7.38 \\
(0.13)\end{array}$ & $\begin{array}{c}0.52 \\
(0.30)\end{array}$ \\
\hline 10 & 2.47 & 4 & - & 4 & $\begin{array}{l}53.2 \\
(5.4)\end{array}$ & $\begin{array}{l}12.6 \\
(2.6)\end{array}$ & $\begin{array}{c}2.5 \\
(1.2)\end{array}$ & $\begin{array}{c}0.08 \\
(0.07)\end{array}$ & $\begin{array}{c}8.32 \\
(0.45)\end{array}$ & $\begin{array}{c}0.60 \\
(0.30)\end{array}$ \\
\hline 11 & 1.15 & 5 & 5 & - & $\begin{array}{c}4.4 \\
(2.3)\end{array}$ & $\begin{array}{c}0.3 \\
(0.1)\end{array}$ & $\begin{array}{l}103.6 \\
(12.1)\end{array}$ & $\begin{array}{c}0.68 \\
(0.09)\end{array}$ & $\begin{array}{c}6.23 \\
(1.73)\end{array}$ & $\begin{array}{c}2.65 \\
(4.82)\end{array}$ \\
\hline N1850 & & & & & 81.4 & 4.1 & 1.2 & -0.03 & 9.69 & 3.4 \\
\hline $\begin{array}{r}\text { All } \\
\text { sample }\end{array}$ & & & & & $\begin{array}{c}26.2 \\
(23.0)\end{array}$ & $\begin{array}{c}1.3 \\
(2.1)\end{array}$ & $\begin{array}{c}9.6 \\
(17.8)\end{array}$ & $\begin{array}{c}0.60 \\
(0.25)\end{array}$ & $\begin{array}{c}7.23 \\
(1.45)\end{array}$ & $\begin{array}{c}2.75 \\
(3.82)\end{array}$ \\
\hline
\end{tabular}

* - number of Galactic globular clusters

** - number of LMC globular clusters

Each group consists of a few taxons. The first group contains 121 Galaxy globular clusters, the second - 49 LMC and 15 Galaxy ones. The members of taxons have parameters confined to fairly narrow intervals.

In the diagrams joining the cluster descriptors pairwise there are regions of complete (or predominant) concentration of clusters belonging to the same taxon, but there are also some regions of overlapping. The corresponding taxons are not isolated but merge continuously one into another.

If we turn to the free parameters, we see that luminosity proves to be insensitive to taxonomy. However, the difference in color and mass takes place. There is a considerable part of old LMC clusters in the mixed taxons. 
The main result is the following. As in the case of Galaxy, LMC globular clusters form a continuous multitude. This probably points to the continuity of the process of forming the totality of these clusters. Though LMC clusters essentially differ in color and in mass, in the space of their dynamical parameters some part of them are reminiscent of Galaxy globular clusters.

\section{References}

Chrysovergis, M., Kontizas, M., \& Kontizas, E. 1989, A\&AS, 77, 357 Eigenson, A. M., \& Yatsyk, O. S. 1995, AZh, 72, 641

Harris, W. E. 1996, AJ, 112, 1487

Kontizas, M., Chrysovergis, M., \& Kontizas, E. 1987, A\&AS, 68, 147 